Check for updates

Cite this: RSC Adv., 2017, 7, 27619

Received 20th April 2017 Accepted 13th May 2017

DOI: $10.1039 / \mathrm{c} 7 \mathrm{ra0} 4451 \mathrm{~h}$

rsc.li/rsc-advances

\section{Catalytic oxidation of organic pollutants in wastewater via a Fenton-like process under the catalysis of $\mathrm{HNO}_{3}$-modified coal fly ash}

\begin{abstract}
Nannan Wang, (D) a Qiang Zhao and Aili Zhang*c
The performance of acid-modified coal fly ash (CFA) was tested for use as a catalyst of a Fenton-like process in $p$-nitrophenol ( $p$-NP) wastewater treatment. The results show that $\mathrm{HNO}_{3}$-modified coal fly ash (HFA) has a better catalytic capacity ( $96.6 \% p$-NP removal rate) than those ( $<92 \% p$-NP removal rate) of CFA modified by other acids $\left(\mathrm{HCl}, \mathrm{H}_{2} \mathrm{SO}_{4}\right.$, and $\left.\mathrm{H}_{3} \mathrm{PO}_{4}\right)$. The removal rate of the $p$-NP by the adsorption of $\mathrm{HFA}$ is less than $2.96 \%$, which can be thought of as negligible compared to that removed by the catalytic oxidation process. Under the optimum experimental conditions (reaction time $=60 \mathrm{~min}, \mathrm{C}_{\mathrm{H}_{2} \mathrm{O}_{2}}=170 \mathrm{mg} \mathrm{L}^{-1}, \mathrm{C}_{\mathrm{HFA}}=10.0 \mathrm{~g}$ $\mathrm{L}^{-1}, \mathrm{pH}=2.0$, mixing speed $=150 \mathrm{rpm}$, and temperature $=25^{\circ} \mathrm{C}$ ), a $98 \% \mathrm{p}$-NP removal rate is observed. HFA has an acute response to the change of temperature and higher temperature is welcomed $(9.3 \%$ and $98 \%$ of the $p$-NP was removed at 25 and $50^{\circ} \mathrm{C}$, respectively, at 5 min). HFA can be reused 9 times with $>91 \%$ of the $p$-NP removal rate, revealing an outstanding catalytic stability and reusability. The catalytic mechanism of HFA was discussed by comparing the physicochemical features of HFA with raw CFA and by proposing the reactions which occur in the Fenton-like process.
\end{abstract}

\section{Introduction}

In recent years, significant progress in treating refractory wastewater has been achieved by the application of advanced oxidation processes (AOPs). A common feature of AOPs is the generation of hydroxyl radicals $\left({ }^{\circ} \mathrm{OH}\right)$, which can decompose refractory organics effectively due to their strong oxidising ability $\left(E_{0}=2.8 \mathrm{~V}\right)$. The Fenton process, as a classic AOP, can generate ${ }^{\circ} \mathrm{OH}$ via the reaction of $\mathrm{Fe}^{2+}$ with $\mathrm{H}_{2} \mathrm{O}_{2}$. The reactions that occur in the Fenton process can be described as follows: $:^{1-3}$

$$
\begin{gathered}
\mathrm{Fe}^{2+}+\mathrm{H}_{2} \mathrm{O}_{2} \rightarrow \mathrm{Fe}^{3+}+\mathrm{OH}^{-}+\cdot \mathrm{OH} \\
\mathrm{Fe}^{3+}+\mathrm{H}_{2} \mathrm{O}_{2} \rightarrow \mathrm{Fe}^{2+}+\mathrm{HO}_{2}^{\cdot}+\mathrm{H}^{+} \\
\mathrm{Fe}^{2+}+\cdot \mathrm{OH} \rightarrow \mathrm{Fe}^{3+}+\mathrm{OH}^{-} \\
\mathrm{H}_{2} \mathrm{O}_{2}+\cdot \mathrm{OH} \rightarrow \mathrm{H}_{2} \mathrm{O}+\mathrm{HO}_{2}^{\cdot} \\
\cdot \mathrm{OH}+\cdot \mathrm{OH} \rightarrow \mathrm{H}_{2} \mathrm{O}_{2}
\end{gathered}
$$$$
\cdot \mathrm{OH}+\text { organics } \rightarrow \text { intermediates } \rightarrow \text { inorganics }
$$

\footnotetext{
${ }^{a}$ School of Mechanical Engineering, Beijing Institute of Petrochemical Technology, Beijing 102617, PR China. E-mail:wnn_flying@163.com

${ }^{b}$ Beijing BHT Environment Technology Co., Ltd, Beijing 100102, PR China

${ }^{c}$ School of Environmental Science and Technology, Dalian University of Technology, Dalian 116024, PR China.E-mail: zal58@163.com
}

Although the Fenton process can oxidize a wide variety of organics, and is even be able to destroy them to produce carbon dioxide $\left(\mathrm{CO}_{2}\right)$, water $\left(\mathrm{H}_{2} \mathrm{O}\right)$ and inorganic salts (eqn (6)), the recycling of the catalyst $\left(\mathrm{Fe}^{2+}\right)$ cannot be easily achieved, leading to the generation of sludge containing Fe ions. The treatment of the sludge is expensive in terms of labour, reagents, and time, and is complex in operation. Thus, exploring a novel solid catalyst that can be used in heterogeneous Fenton-like processes is necessary.

Coal fly ash (CFA) is produced from steel mills and coal-fired power plants. Over 300 billion tons of CFA is produced every year in the world. ${ }^{4}$ Even now, CFA is still mainly treated by means of landfill, causing severe environmental pollution because of the leaching of the metallic elements that are contained in CFA. Thus, proper treatment of CFA is required. Over the years, many studies ${ }^{5-14}$ have revealed that pre-treated CFA can be used as an effective low-cost adsorbent for the removal of organic and inorganic metallic elements (such as arsenic, nickel, calcium, copper, iron and manganese ions) in wastewater. However, the catalytic property of CFA has not attracted enough attention and just a small number of studies ${ }^{15-17}$ have been conducted until now. Reassuringly, these studies show that the application of pre-modified CFA as a heterogeneous catalyst could have enormous potential due to the existence of transition metal oxides. The modification of CFA can be achieved by acid modification, alkali modification, and thermal modification. ${ }^{18-20}$ However, alkali modification and thermal modification can introduce alkaline substances and destroy the space structure of CFA, respectively, which have adverse effects 
on the catalytic capacity of a catalyst. Therefore, acid modification is always used to prepare the target catalyst.

The contamination of aquatic environments by chemical pollutants has been a major issue in recent years. $p$-Nitrophenol ( $p$-NP) is typically one of the most refractory substances that is present in industrial wastewater, due to its high solubility and stability in water. $p$-NP exists in wastewater from a number of industries, such as textiles, paper and pulp, plastics etc., and is considered to be a hazardous chemical pollutant. The use of $p$ NP has been seriously controlled by the U.S. Environmental Protection Agency. ${ }^{21}$ The maximum allowed concentration in water is in the range 1-20 ppb. Hence, its removal from industrial effluents is an important practical problem.

In this paper, in order to promote the application of CFA, a comprehensive study about CFA modification using $\mathrm{HNO}_{3}$ (HFA) was conducted and its catalytic capacity was investigated by catalysing a heterogeneous Fenton-like process to degrade $p$ NP in wastewater. Firstly, the preparation conditions of HFA were optimized after choosing $\mathrm{HNO}_{3}$ as the proper acid in the modification, and then the removal kinetics of $p$-NP in wastewater were investigated. After that, the reusability and stability of HFA were tested. Finally, the catalytic mechanism of HFA was proposed based on the investigation of (I) the effect of the HFA adsorption capacity, (II) a comparison of the chemical and physical features of HFA with those of CFA, and (III) the possible reactions that occur on the surface of HFA and in the solution.

\section{Materials and methods}

\subsection{Chemicals and reagents}

p-NP (analytical grade) was purchased from Tianjin Kermel Chemical Reagent Co., Ltd., China and was used without any further purification. The $p$-NP wastewater $\left(100 \mathrm{mg} \mathrm{L}^{-1}\right)$ was prepared directly by diluting solid $p$-NP into distilled water. The hydrogen peroxide $\left(\mathrm{H}_{2} \mathrm{O}_{2}\right)(30 \%$, w/w), sodium hydroxide $(\mathrm{NaOH})$, nitric acid $\left(\mathrm{HNO}_{3}\right)$, sulphuric acid $\left(\mathrm{H}_{2} \mathrm{SO}_{4}\right)$, hydrochloric acid $(\mathrm{HCl})$, and phosphoric acid $\left(\mathrm{H}_{3} \mathrm{PO}_{4}\right)$ that were used in this work were of analytical grade. $\mathrm{H}_{2} \mathrm{O}_{2}$ was used directly without dilution. $\mathrm{NaOH}$ and different acids were dissolved and diluted, respectively, with distilled water to achieve the target concentrations. The CFA that was used was purchased from a coal-fired power plant in China (source not revealed due to a confidentiality agreement).

\subsection{Preparation of HFA}

Due to the existence of some impurities (such as fibers and alkaline substances) on its surface, the CFA was first washed repeatedly and adequately with distilled water before modification until the $\mathrm{pH}$ of the supernatant was equal to the $\mathrm{pH}$ value of distilled water. The loading of CFA in distilled water was $10.0 \mathrm{~g} \mathrm{~L}^{-1}$. We used adequate agitation to promote the washing quality. After $12 \mathrm{~h}$, the mechanical agitation was stopped and the mixture was precipitated and separated. After the washing, the washed CFA was dried at $105{ }^{\circ} \mathrm{C}$ until the weight did not change.
During the stage of modification, the washed-dried CFA was soaked in a $1 \mathrm{~mol} \mathrm{~L}^{-1} \mathrm{HNO}_{3}$ solution (CFA loading $=25 \mathrm{~g} \mathrm{~L}^{-1}$ ). The mixture was stirred using a magnetic stirrer (350 rpm) for 4 h. Subsequently, the mixture was precipitated by gravity, layered, and filtered using a vacuum filter. The solid that was obtained after the filtration was dried at $105^{\circ} \mathrm{C}$ until the weight stayed constant. The CFA obtained after the above processes (i.e., HFA) was stored in a drying basin for the following experiments.

\subsection{Treatment procedure of $\boldsymbol{p}$-NP wastewater}

$100 \mathrm{~mL}$ of $p$-NP solution (100 $\left.\mathrm{mg} \mathrm{L}^{-1}\right)$ with a $\mathrm{pH}$ pre-adjusted using $\mathrm{NaOH}$ and $\mathrm{HNO}_{3}$ was prepared in a beaker $(500 \mathrm{~mL})$, and the temperature of the solution was controlled using a water bath. After the temperature reached the determined value $\left( \pm 1{ }^{\circ} \mathrm{C}\right)$, a certain amount of HFA was added into the solution and mixed using a mechanical agitator. The wastewater treatment started as soon as $\mathrm{H}_{2} \mathrm{O}_{2}$ was added into the beaker.

During the reaction, the mixture was sampled at specific time intervals. Meanwhile, the $\mathrm{NaOH}$ solution was added into the sample immediately to stop the catalytic oxidation process. All of the samples were filtrated using a vacuum pump and the filtrate was analysed to determine the concentration of the residual $p$-NP.

In the study of the reusability and stability of the HFA, the solid that was separated from the treated wastewater was washed using distilled water and dried until a constant weight was achieved at $105{ }^{\circ} \mathrm{C}$. After that, the used HFA was reused again until the removal efficiency of $p$-NP had an obvious decrease.

For the investigation of the adsorption effect of the HFA, the adsorption isotherm was measured under fixed experimental conditions (the reaction temperature was $25{ }^{\circ} \mathrm{C}$, the reaction time was $60 \mathrm{~min}$, which is long enough to reach to the adsorption equilibrium, the $\mathrm{pH}$ was 2.0 , the HFA loading was $10.0 \mathrm{~g} \mathrm{~L}^{-1}$, and the $V_{p \text {-NP }}$ value was $100 \mathrm{~mL}$ ) while only the $p$-NP concentration changed $(1,3,7,10,15,20,30,40,50,60,70,80$, and $90 \mathrm{mg} \mathrm{L}^{-1}$ ). The maximum adsorption capacity of the HFA was obtained from the adsorption isotherm.

\subsection{Characterization of HFA}

The surface morphology of CFA and HFA was measured using a BET (Brunauer-Emmett-Teller) automated analyser (QUADRASORB). The analysis gas, outgas time and outgas temperature were nitrogen, $5.0 \mathrm{~h}$ and $300{ }^{\circ} \mathrm{C}$, respectively.

The chemical composition of CFA and HFA was determined using X-ray fluorescence spectroscopy (XRF-1800). The maximum pipe pressure, maximum current, scanning speed, the temperature of the spectrum chamber, and power were 40 $\mathrm{kV}, 90 \mathrm{~mA}, 20^{\circ} \mathrm{min}^{-1}, 30 \pm 0.1{ }^{\circ} \mathrm{C}$, and $36 \mathrm{~kW}$, respectively.

The morphology of the samples was analysed using scanning electron microscopy (SEM, JEOL, Japan) with an acceleration voltage of $15 \mathrm{kV}$ and a current of $2 \times 10^{-11} \mathrm{~A}$. The ambient temperature and humidity were $16{ }^{\circ} \mathrm{C}$ and $60 \%$, respectively. 
The crystal structure of the samples was determined using Xray diffraction (XRD) (Bruker, Germany) at room temperature with monochromatic high-intensity $\mathrm{Cu} \mathrm{K}_{\alpha}$ radiation $(l=1.5406$ $\AA)$, an accelerating voltage of $40 \mathrm{kV}$ and an emission current of $30 \mathrm{~mA}$. The scanning range of $2 \theta$ and the scanning speed were $10-70^{\circ}$ and $4^{\circ} \min ^{-1}$, respectively.

\subsection{Analytical methods}

Due to the fact that $p$-NP has its maximum UV-vis absorption peak at $400 \mathrm{~nm}$ at $\mathrm{pH}>11$ (Fig. 1), the concentration of the residual $p$-NP in wastewater after the treatment was measured using a UV-vis spectrophotometer (JASCO V-560, Japan) under the above conditions. The removal rate of $p$-NP was calculated by:

$$
\text { Removal rate }(\%)=\left(C_{0}-C_{\mathrm{t}}\right) / C_{0} \times 100 \%
$$

where $C_{0}$ and $C_{\mathrm{t}}$ are the initial and instantaneous concentrations of $p$-NP $\left(\mathrm{mg} \mathrm{L}^{-1}\right)$.

\section{Results and discussion}

\subsection{Effect of the acid type}

Some studies ${ }^{22-25}$ show that the acid type has an effect on the catalytic capacity of HFA. In this work, four different acids $\left(\mathrm{HNO}_{3}, \mathrm{HCl}, \mathrm{H}_{2} \mathrm{SO}_{4}\right.$ and $\left.\mathrm{H}_{3} \mathrm{PO}_{4}\right)$ were chosen and tested. The results are given in Table 1 . We can see that the CFA modified by $\mathrm{H}_{3} \mathrm{PO}_{4}$ has the worst performance in the catalytic degradation of $p$-NP $\left(87.9 \%\right.$ for the $p$-NP removal rate) while the $\mathrm{HNO}_{3}$-modified CFA has the best catalytic capacity $(96.6 \%$ for the $p$-NP removal rate). Additionally, the CFA modified by $\mathrm{HCl}$ and $\mathrm{H}_{2} \mathrm{SO}_{4}$ has intermediate performance.

The difference could be caused by the different ionization equilibrium constants (calculated using eqn (8) and (9)) of the acids and the corresponding calcium salt.

$$
\begin{gathered}
\mathrm{HIn} \leftrightarrow \mathrm{H}^{+}+\mathrm{In}^{-} \\
K_{\mathrm{a}}=\frac{\left[\mathrm{H}^{+}\right] \times\left[\mathrm{In}^{-}\right]}{[\mathrm{HIn}]}
\end{gathered}
$$

$\mathrm{H}_{2} \mathrm{SO}_{4}$ molecules can ionize completely and generate $\mathrm{H}^{+}$and $\mathrm{HSO}_{4}{ }^{-}$. The $K_{\mathrm{a}}$ value of $\mathrm{HSO}_{4}{ }^{-}$is equal to $1.02 \times 10^{-2}$ at $25^{\circ} \mathrm{C}$

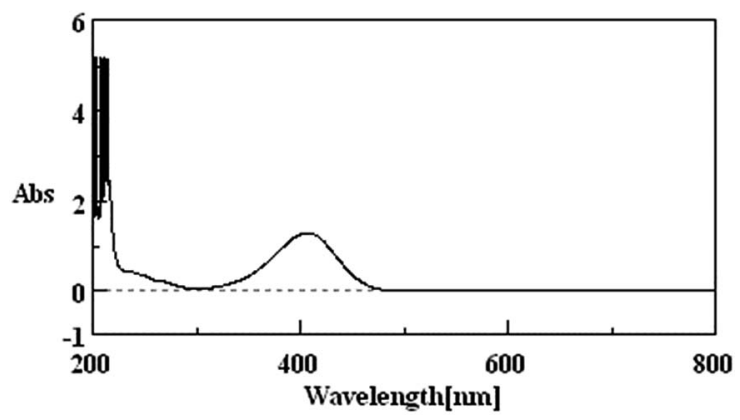

Fig. 1 The absorption curve of $p$-NP.
Table 1 Comparison of the degradation rates of $p$-NP by different acid-modified coal fly ash $\left(T=25^{\circ} \mathrm{C}, \mathrm{pH}=2.0, \mathrm{C}_{\mathrm{H}_{2} \mathrm{O}_{2}}=330 \mathrm{mg} \mathrm{L}^{-1}\right.$, activated CFA loading $=10 \mathrm{~g} \mathrm{~L}^{-1}$, and reaction time $=40 \mathrm{~min}$ )

\begin{tabular}{ll}
\hline Type of HFA & $\begin{array}{l}\text { Removal rate } \\
\text { of } p \text {-NP/\% }\end{array}$ \\
\hline $\mathrm{HNO}_{3}$-activated CFA & 96.6 \\
$\mathrm{HCl}^{-a c t i v a t e d ~ C F A ~}$ & 91.4 \\
$\mathrm{H}_{2} \mathrm{SO}_{4}$-activated CFA & 90.4 \\
$\mathrm{H}_{3} \mathrm{PO}_{4}$-activated CFA & 87.9
\end{tabular}

(Table 2). By comparison, $\mathrm{H}_{3} \mathrm{PO}_{4}$ ionizes partially and the three equilibrium constants $\left(7.11 \times 10^{-3}, 6.23 \times 10^{-8}\right.$, and $4.50 \times$ $10^{-13}$ ) are much lower than those of $\mathrm{H}_{2} \mathrm{SO}_{4}$ (a strong electrolyte) and $\mathrm{HSO}_{4}{ }^{-}$(a weak electrolyte). Thus, the acid modification using $\mathrm{H}_{3} \mathrm{PO}_{4}$ is weaker than that using $\mathrm{H}_{2} \mathrm{SO}_{4}$ because of the lower $\mathrm{H}^{+}$concentration in the $\mathrm{H}_{3} \mathrm{PO}_{4}$ solution.

During the $\mathrm{H}_{2} \mathrm{SO}_{4}$ modification, the generated $\mathrm{CaSO}_{4}$ and $\mathrm{Ca}\left(\mathrm{HSO}_{4}\right)_{2}$ are weak electrolytes and can cover the surface of HFA. In contrast, the $\mathrm{CaCl}_{2}$ and $\mathrm{Ca}\left(\mathrm{NO}_{3}\right)_{2}$ can completely dissolve in water with no possibility of covering the surface of HFA. This could be the reason that the $\mathrm{H}_{2} \mathrm{SO}_{4}$-modified CFA has a weak catalytic capacity compared to that of $\mathrm{HNO}_{3}$ and $\mathrm{HCl}-$ modified CFA.

As for the $\mathrm{HCl}$ and $\mathrm{HNO}_{3}$ modification, both of the two acids and the corresponding calcium salts are strong electrolytes, and the "cover effect" cannot occur. The difference in the catalytic capacity of $\mathrm{HNO}_{3}$-modified and HCl-modified CFA still needs further study.

\subsection{Optimization of the influencing factors on Fenton-like processes and the proposed degradation product of $p$-NP}

Previous studies ${ }^{26,27}$ show that the variation of the treatment time, $\mathrm{H}_{2} \mathrm{O}_{2}$ dosage, catalyst loading, wastewater $\mathrm{pH}$ and mixing speed have an effect on the treatment efficiency of wastewater. Therefore, they were investigated in detail in this work. Fig. 2 shows the effect of the above parameters on the removal rate of $p$-NP. We can see that the $\mathrm{H}_{2} \mathrm{O}_{2}$ dosage, HFA loading and mixing speed have a similar effect on the $p$-NP removal rate, namely, insufficient $\mathrm{H}_{2} \mathrm{O}_{2}$ dosage, HFA loading and/or mixing speed could cause the decrease of the removal rate of $p$-NP. The removal rate reaches a plateau when the $\mathrm{H}_{2} \mathrm{O}_{2}$ dosage, HFA loading and mixing speed reach the critical point $\left(\mathrm{H}_{2} \mathrm{O}_{2}\right.$ dosage $=170 \mathrm{mg} \mathrm{L}^{-1}$, HFA loading $=10.0 \mathrm{~g} \mathrm{~L}^{-1}$ and mixing speed $=150 \mathrm{rpm})$. It is economical to set the three critical points as the optimum values to achieve the best $p$-NP removal efficiency simultaneously.

Table 2 Ionization equilibrium constants of $\mathrm{H}_{2} \mathrm{SO}_{4}$ and $\mathrm{H}_{3} \mathrm{PO}_{4}$ at 25 ${ }^{\circ} \mathrm{C}$

\begin{tabular}{llll}
$\begin{array}{l}\text { Type of } \\
\text { acid }\end{array}$ & $K_{\mathrm{a} 1}$ & $K_{\mathrm{a} 2}$ & $K_{\mathrm{a} 3}$ \\
\hline $\mathrm{H}_{2} \mathrm{SO}_{4}$ & - & $1.02 \times 10^{-2}$ & - \\
$\mathrm{H}_{3} \mathrm{PO}_{4}$ & $7.11 \times 10^{-3}$ & $6.23 \times 10^{-8}$ & $4.50 \times 10^{-13}$
\end{tabular}






Fig. 2 Effects of the experimental parameters on the removal rate of $p$-NP ((a) $T=25^{\circ} \mathrm{C}, \mathrm{pH}=2, C_{\mathrm{H}_{2} \mathrm{O}_{2}}=170 \mathrm{mg} \mathrm{L}^{-1}, C_{p-\mathrm{NP}}=100 \mathrm{mg} \mathrm{L}^{-1}$ and $C_{\mathrm{HFA}}=10.0 \mathrm{~g} \mathrm{~L}^{-1}$; (b) $T=25^{\circ} \mathrm{C}, \mathrm{pH}=2.0, t=60 \mathrm{~min}, C_{p-\mathrm{NP}}=$ $100 \mathrm{mg} \mathrm{L}^{-1}$ and $C_{\mathrm{HFA}}=10.0 \mathrm{~g} \mathrm{~L}^{-1}$; (c) $\mathrm{T}=25^{\circ} \mathrm{C}_{,} \mathrm{C}_{\mathrm{H}_{2} \mathrm{O}_{2}}=170 \mathrm{mg} \mathrm{L}^{-1}$, $t=60 \mathrm{~min}, \mathrm{C}_{p-\mathrm{NP}}=100 \mathrm{mg} \mathrm{L}^{-1}$ and $\mathrm{pH}=2.0$; (d) $T=25^{\circ} \mathrm{C}, \mathrm{C}_{\mathrm{H}_{2} \mathrm{O}_{2}}=$ $170 \mathrm{mg} \mathrm{L}^{-1}, t=60 \mathrm{~min}, C_{p-\mathrm{NP}}=100 \mathrm{mg} \mathrm{L}^{-1}$ and $C_{\mathrm{HFA}}=10.0 \mathrm{~g} \mathrm{~L}^{-1}$; and (e) $T=25^{\circ} \mathrm{C}, \mathrm{pH}=2.0, C_{\mathrm{H}_{2} \mathrm{O}_{2}}=170 \mathrm{mg} \mathrm{L}^{-1}, t=60 \mathrm{~min}, C_{p-\mathrm{NP}}=$ $100 \mathrm{mg} \mathrm{L}^{-1}$, and $C_{\mathrm{HFA}}=10.0 \mathrm{~g} \mathrm{~L}^{-1}$ ).

The treatment time and $\mathrm{pH}$ have a distinct effect on the removal rate of $p$-NP. For the reaction time, the $p$-NP removal rate firstly rapidly rises and then reaches a plateau after $60 \mathrm{~min}$. For the $\mathrm{pH}$, the $p$-NP removal rate has its highest value at $\mathrm{pH}=$ 2 , and a lower or higher $\mathrm{pH}$ has a negative effect on the effective treatment of wastewater.

According to the statement above, we can pick the optimum experimental conditions, i.e., reaction time $=60 \mathrm{~min}, \mathrm{H}_{2} \mathrm{O}_{2}$ dosage $=170 \mathrm{mg} \mathrm{L}^{-1}$, HFA loading $=10.0 \mathrm{~g} \mathrm{~L}^{-1}, \mathrm{pH}=2.0$, and mixing speed $=150 \mathrm{rpm}$. In this situation, the removal rate of $p$ NP is no less than $98 \%$.

The results in some previous studies ${ }^{28-30}$ show that the addition of an organic acid is helpful to increase the degradation of the pollutants. Because citrate and oxalate are typical in these kinds of studies, ${ }^{26}$ the effects of citrate $\left(0.5 \mathrm{mmol} \mathrm{L}^{-1}\right)$ and oxalate $\left(0.5 \mathrm{mmol} \mathrm{L}^{-1}\right)$ on the removal rate of $p$-NP were investigated, under the optimal experimental conditions that are given above. We find that the addition of an organic acid can decrease the removal rate of $p$-NP from $98 \%$ (without adding the organic acid) to $71.8 \%$ (adding citrate) and $77.6 \%$ (adding oxalate). This result is different from those of some studies. ${ }^{28-30}$

The experimental conditions used in these cited papers ${ }^{28-30}$ are different from ours, i.e., all of the studies in the cited papers are carried out under the irradiation of light (ultraviolet or visible light), which can obviously promote iron redox cycling by the reaction of $\mathrm{Fe}^{\mathrm{III}}-\mathrm{L}+h \nu \rightarrow \mathrm{Fe}^{\mathrm{II}}+\mathrm{L}^{+} .^{26}$

In our study, we do not apply the photo-Fenton process, so the redox cycling of iron cannot occur. Instead, the active sites of HFA are occupied and a portion of the ${ }^{\circ} \mathrm{OH}$ radicals is consumed competitively by the organic acid.

The degradation product/path of $p$-NP has been previously investigated in some studies. ${ }^{31-33}$ From these studies, we can find the analogous degradation path of $p$-NP. Hydroquinone (HQ) and 4-nitrocatechol (4-NC) can always be produced by the attack of ${ }^{\circ} \mathrm{OH}$ on the nitro-group of $p$-NP and the entering of 'OH to the ortho position of $p$-NP. Meanwhile, the two products (HQ and 4-NC) can react with ${ }^{\circ} \mathrm{OH}$ to form 1,2,4-benzenetriol $(1,2,4-\mathrm{BT}){ }^{31,32}$ Further reaction of $1,2,4-\mathrm{BT}$ with ${ }^{\circ} \mathrm{OH}$ can generate some chain organic compounds, such as maleic acid, fumaric acid, oxalic acid and formic acid, by opening the ring. ${ }^{32}$ These chain compounds can be oxidized further by ${ }^{\circ} \mathrm{OH}$ as well to carbon dioxide and, eventually, water.

\subsection{Kinetics of $p$-NP degradation}

The hydroxyl radical, as the strong oxidative radical, can be generated in heterogeneous Fenton-like processes and attack $p$ NP molecules as shown in eqn (10).

$$
p-\mathrm{NP}+\mathrm{OH}^{\cdot} \stackrel{k_{\mathrm{i}}}{\longrightarrow} \text { product }
$$

Its kinetics procedure can be characterized using:

$$
-\frac{\mathrm{d} C_{p-\mathrm{NP}}}{\mathrm{d} t}=k_{\mathrm{i}} \times C_{\cdot \mathrm{OH}} \times C_{p-\mathrm{NP}}
$$

where $k_{\mathrm{i}}$ is the intrinsic reaction rate constant $\left(\mathrm{L} \mathrm{mol}^{-1} \mathrm{~s}^{-1}\right)$.

Assuming the concentration of ${ }^{\circ} \mathrm{OH}$ remains constant, eqn (11) becomes:

$$
-\frac{\mathrm{d} C_{p-\mathrm{NP}}}{\mathrm{d} t}=k_{\mathrm{ap}} \times C_{p-\mathrm{NP}}
$$

Therefore,

$$
\ln \frac{C_{p-\mathrm{NP}}}{C_{0, p-\mathrm{NP}}}=-k_{\mathrm{ap}} \times t
$$

where $C_{0, p \text {-NP }}$ represents the initial concentration of $p$-NP (mg $\left.\mathrm{L}^{-1}\right)$, and $k_{\mathrm{ap}}$ is the pseudo first-order rate constant $\left(\mathrm{min}^{-1}\right)$, which can be determined from the slope of a $\ln \frac{C_{p-\mathrm{NP}}}{C_{0, p \text {-NP }}}$ versus time graph.

3.3.1 $\mathrm{H}_{2} \mathrm{O}_{2}$ dosage. $\mathrm{H}_{2} \mathrm{O}_{2}$, as the source of ${ }^{\circ} \mathrm{OH}$, plays an important role in heterogeneous Fenton-like processes. It was reported that a catalyst alone cannot eliminate a contaminant effectively, revealing that $\mathrm{H}_{2} \mathrm{O}_{2}$ is essential. ${ }^{34}$ As shown in eqn (14), the molar ratio of $p$-NP to $\mathrm{H}_{2} \mathrm{O}_{2}$ in theory is $1: 14$, under which $p$-NP can be mineralized completely by $\mathrm{H}_{2} \mathrm{O}_{2}$, i.e., $10 \mathrm{mmol} \mathrm{L}^{-1}$ (340 $\left.\mathrm{mg} \mathrm{L}^{-1}\right) \mathrm{H}_{2} \mathrm{O}_{2}$ is needed for the purpose of oxidizing $0.719 \mathrm{mmol} \mathrm{L}^{-1}\left(100 \mathrm{mg} \mathrm{L}^{-1}\right) p$-NP to $\mathrm{CO}_{2}$ and $\mathrm{H}_{2} \mathrm{O}_{2}$ completely. 


$$
\mathrm{C}_{6} \mathrm{H}_{5} \mathrm{NO}_{3}+14 \mathrm{H}_{2} \mathrm{O}_{2} \rightarrow 6 \mathrm{CO}_{2}+16 \mathrm{H}_{2} \mathrm{O}+\mathrm{HNO}_{3}
$$

Taking the cost of treating wastewater into consideration, $340 \mathrm{mg} \mathrm{L}^{-1}$ was used as the maximum concentration and 85$340 \mathrm{mg} \mathrm{L}^{-1}$ was chosen for investigating the effect of $\mathrm{H}_{2} \mathrm{O}_{2}$. As shown in Fig. 3, the degradation of $p$-NP accords with the pseudo-first order kinetics and the degradation rate constant increases from $0.041 \mathrm{~min}^{-1}$ to $0.116 \mathrm{~min}^{-1}$ with the increase of $\mathrm{H}_{2} \mathrm{O}_{2}$ dosage from $85 \mathrm{mg} \mathrm{L}^{-1}$ to $340 \mathrm{mg} \mathrm{L}^{-1}$ (Table 3). In this situation, the maximum removal rate of $p$-NP can reach $98 \%$ within 30 min at a $340 \mathrm{mg} \mathrm{L}^{-1} \mathrm{H}_{2} \mathrm{O}_{2}$ dosage.

According to the literature, ${ }^{35,36}$ the $\mathrm{H}_{2} \mathrm{O}_{2}$ dosage should have an appropriate range. When the $\mathrm{H}_{2} \mathrm{O}_{2}$ dosage is excessive, the degradation rate of $p$-NP would decrease with the increase of the $\mathrm{H}_{2} \mathrm{O}_{2}$ dosage. This could be attributed to the reaction of ${ }^{\circ} \mathrm{OH}$ with $\mathrm{H}_{2} \mathrm{O}_{2}$ and the reaction of two ${ }^{\circ} \mathrm{OH}$ radicals (see eqn (4) and (5)). Both of the two side reactions inhibit the effective utilization of $\mathrm{H}_{2} \mathrm{O}_{2}$ and the rapid oxidation of $p$-NP.

When the $\mathrm{H}_{2} \mathrm{O}_{2}$ dosage is deficient $\left(85 \mathrm{mg} \mathrm{L}^{-1}\right)$, the removal rate of $p$-NP would have an obvious decrease due to the insufficiency of the oxidizing reagent ( $\left.{ }^{\circ} \mathrm{OH}\right)$. The results in this work are in good agreement with the results in the previous studies. ${ }^{37-39}$

3.3.2 HFA loading. The effect of HFA loading was investigated over the range from 3.0 to $20.0 \mathrm{~g} \mathrm{~L}^{-1}$. The experimental results are given in Fig. 4 and Table 4 . As shown in Fig. 4, the experimental data presents sound pseudo first-order kinetic behaviour. According to Table 4 , the $k_{\text {ap }}$ value increases from 0.006 to $0.236 \mathrm{~min}^{-1}$ over the whole range of HFA loadings. Thus, the optimal HFA loading in this work "seems" to be more than $20.0 \mathrm{~g} \mathrm{~L} \mathrm{~L}^{-1}$. However, before determining the "true" optimal HFA loading it is better to investigate some other factors besides comparing the $k_{\text {ap }}$ values, such as the cost and the time of the wastewater treatment.

The experimental results in this work show that $97 \%$ of the $p$ $\mathrm{NP}$ is removed when the HFA loading is $20.0 \mathrm{~g} \mathrm{~L}^{-1}$ at $25 \mathrm{~min}$, while $95.3 \% p$-NP removal rate is achieved with an HFA loading of $10.0 \mathrm{~g} \mathrm{~L}^{-1}$ at $30 \mathrm{~min}$. Within a similar reaction time approximately the same removal rate of $p$-NP is achieved at 10.0



Fig. 3 Effect of $\mathrm{H}_{2} \mathrm{O}_{2}$ dosage on the $p$-NP degradation kinetics $\left(C_{p}\right.$ $\mathrm{NP}=100 \mathrm{mg} \mathrm{L}^{-1}, \mathrm{~T}=25^{\circ} \mathrm{C}, \mathrm{C}_{\mathrm{HFA}}=10.0 \mathrm{~g} \mathrm{~L}^{-1}$, and $\mathrm{pH}=2.0$ ).
Table 3 The pseudo first-order rate constants $\left(k_{\mathrm{ap}}\right)$ at different $\mathrm{H}_{2} \mathrm{O}_{2}$ dosages

\begin{tabular}{llll}
\hline$\left[\mathrm{H}_{2} \mathrm{O}_{2}\right] / \mathrm{mg} \mathrm{L}^{-1}$ & 340 & 170 & 85 \\
$k_{\mathrm{ap}} / \mathrm{min}^{-1}$ & 0.116 & 0.080 & 0.041
\end{tabular}

and $20.0 \mathrm{~g} \mathrm{~L}^{-1}$ of HFA loading. Comparing the results of those that used $10.0 \mathrm{~g} \mathrm{~L}^{-1}$ with those that used $20.0 \mathrm{~g} \mathrm{~L}^{-1}$, the doubled loading of HFA $\left(20.0 \mathrm{~g} \mathrm{~L}^{-1}\right)$ increased not only the usage amount of HFA, but it also doubled every factor during the preparation of HFA, including, but not limited to: the workload, working hours, and raw materials.

Thus, although increasing the HFA loading can theoretically accelerate the removal rate of $p$-NP, it must be controlled properly in practical applications. In this work, an HFA loading of $10.0 \mathrm{~g} \mathrm{~L}^{-1}$ with a degradation rate constant of $p$-NP of 0.138 $\min ^{-1}$ is enough, and increasing the HFA loading further cannot increase the wastewater treatment efficiency obviously any more, but it does raise the treatment costs dramatically.

3.3.3 $\mathrm{pH}$. The initial $\mathrm{pH}$ has a significant influence on the heterogeneous Fenton-like process during the treatment of organic wastewater. ${ }^{40-42}$ Fig. 5 shows that the removal of $p$-NP complies with pseudo first-order kinetics behaviours according to the fitting curves of the reaction time versus $\ln \left(C / C_{0}\right)$ (see eqn (13)). The maximum absolute value of the slope $\left(k_{\mathrm{ap}}\right)$ emerges at a pH of $2.0\left(0.138 \mathrm{~min}^{-1}\right)$ (Table 5). At pH $=2.0$, the removal rate of $p$-NP is $97.8 \%$ at $40 \mathrm{~min}$.

When the $\mathrm{pH}$ is lower or higher than 2.0, the value of $k_{\mathrm{ap}}$ decreases sharply, i.e., $k_{\mathrm{ap}}=0.007$ versus $\mathrm{pH}=1.0$ and $k_{\mathrm{ap}}=$ 0.002 versus $\mathrm{pH}=3.0$ (Table 5). In this situation, only $44 \%$ $(\mathrm{pH}=1.0) / 12.5 \%(\mathrm{pH}=3.0)$ of the $p$-NP is removed after $60 \mathrm{~min}$. By comparison, controlling the $\mathrm{pH}$ at $\mathrm{pH}=2.0$ is better in the case of pursuing a higher removal efficiency of $p$-NP.

When the $\mathrm{pH}$ increases from 2.0, the oxidation ability of the heterogeneous Fenton-like process decreases due to deactivation of the ferrous ions. At a lower $\mathrm{pH}$ range $(\mathrm{pH}=1.0), \mathrm{H}_{2} \mathrm{O}_{2}$ could be stabilized to $\mathrm{H}_{3} \mathrm{O}_{2}{ }^{+}$, as shown in eqn (15), which can decrease the production rate of ${ }^{\circ} \mathrm{OH}$ indirectly. ${ }^{43}$ In addition, the

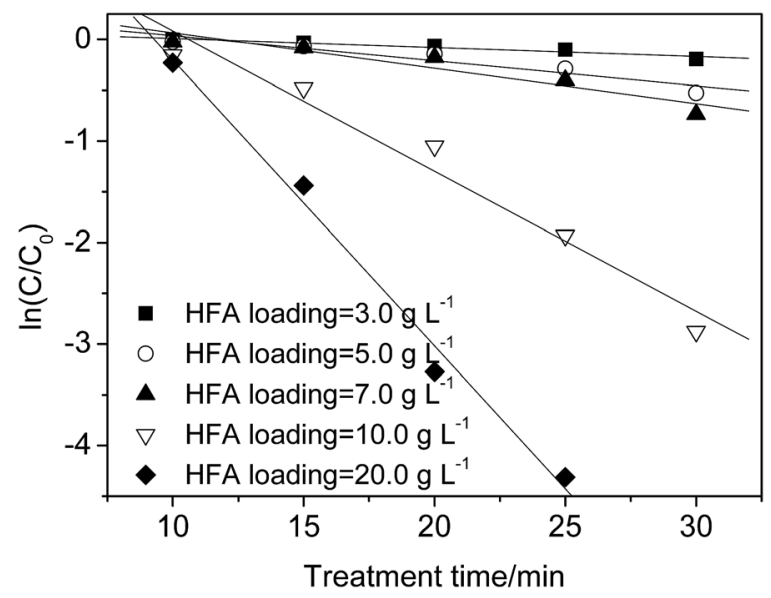

Fig. 4 Effect of HFA loading on the $p$-NP degradation kinetics $\left(C_{p-}\right.$ $\mathrm{NP}=100 \mathrm{mg} \mathrm{L}^{-1}, \mathrm{~T}=25^{\circ} \mathrm{C}, \mathrm{pH}=2.0$, and $\mathrm{C}_{\mathrm{H}_{2} \mathrm{O}_{2}}=170 \mathrm{mg} \mathrm{L}^{-1}$ ). 
Table 4 The pseudo first-order degradation rate constants $\left(k_{\mathrm{ap}}\right)$ at different HFA loadings

\begin{tabular}{llllll}
\hline HFA loading $/ \mathrm{g} \mathrm{L}^{-1}$ & 3.0 & 5.0 & 7.0 & 10.0 & 20.0 \\
$k_{\mathrm{ap}} / \mathrm{min}^{-1}$ & 0.006 & 0.025 & 0.041 & 0.138 & 0.236
\end{tabular}

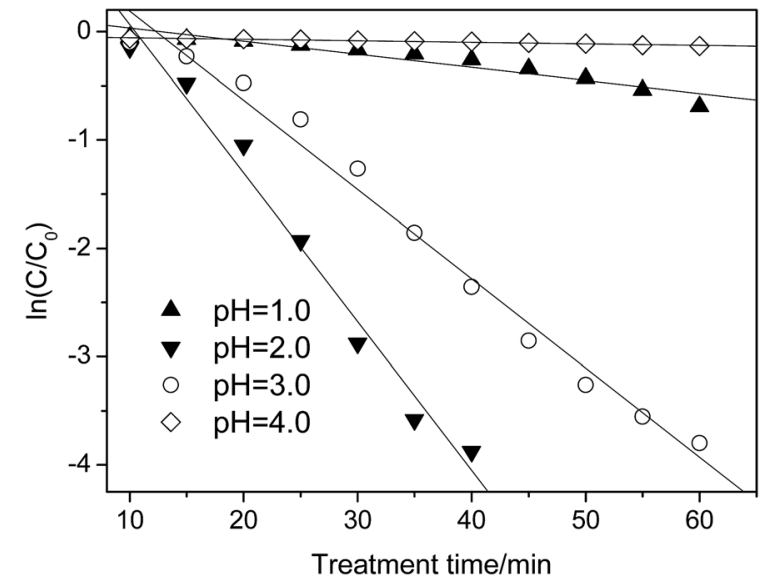

Fig. 5 Effect of $\mathrm{pH}$ on the $p$-NP degradation kinetics $\left(C_{p-\mathrm{NP}}=100 \mathrm{mg}\right.$ $\mathrm{L}^{-1}, \mathrm{C}_{\mathrm{H}_{2} \mathrm{O}_{2}}=170 \mathrm{mg} \mathrm{L}^{-1}, \mathrm{C}_{\mathrm{HFA}}=10.0 \mathrm{~g} \mathrm{~L}^{-1}$, and $\mathrm{T}=25^{\circ} \mathrm{C}$ ).

Table 5 The pseudo first-order degradation rate constants $\left(k_{\mathrm{ap}}\right)$ at different $\mathrm{pH}$ values

\begin{tabular}{lllll}
\hline $\mathrm{pH}$ & 1.0 & 2.0 & 3.0 & 4.0 \\
$k_{\mathrm{ap}} / \mathrm{min}^{-1}$ & 0.007 & 0.138 & 0.002 & -
\end{tabular}

scavenging effect of ${ }^{\circ} \mathrm{OH}$ by $\mathrm{H}^{+}$becomes obvious as well (eqn (16)), which decreases the effective concentration of ${ }^{\circ} \mathrm{OH} .{ }^{44}$

$$
\begin{gathered}
\mathrm{H}_{2} \mathrm{O}_{2}+\mathrm{H}^{+} \rightarrow \mathrm{H}_{3} \mathrm{O}_{2}^{+} \\
\cdot \mathrm{OH}+\mathrm{H}^{+}+\mathrm{e}^{-} \rightarrow \mathrm{H}_{2} \mathrm{O}
\end{gathered}
$$

3.3.4 Temperature. The results in this work show that raising the wastewater temperature can accelerate the elimination of $p$-NP. $98 \%$ of the $p$-NP is removed at $5 \mathrm{~min}$ at both $50{ }^{\circ} \mathrm{C}$ and $75{ }^{\circ} \mathrm{C}$, while only $9.3 \%$ is removed at $25{ }^{\circ} \mathrm{C}$. It is difficult to know the residual concentration of $p$-NP at $<5$ min because the reaction time is too short to determine it exactly when relying on the current instruments. However, we can speculate that $98 \%$ of the $p$-NP could have been removed in less than 5 min at $75{ }^{\circ} \mathrm{C}$.

In light of the above results, the HFA has a sensitive response to a change in temperature. This feature is beneficial for the treatment of wastewater with a higher temperature than room temperature. The determination of specific degradation kinetics of $p$-NP within 5 min can be realized by online detection in later work. The previous studies ${ }^{45,46}$ considered the effect of the temperature as well, but not adequately. Considering the results in this work, a detailed study of the influence of the temperature on the catalytic capacity of modified CFA is necessary.

\subsection{Reusability and stability of HFA}

For the heterogeneous Fenton-like process, evaluating the reusability and stability of the catalyst is significant for the purpose of industrial implementation because it is related to the cost of the wastewater treatment. The results in this study reveal that the $\mathrm{pH}$ has a remarkable effect on the dissolution of Fe due to the reaction of iron oxide on the surface of HFA with $\mathrm{H}^{+}$in the solution. Considering the fact that the catalytic capacity of HFA is mainly from the Fe element, ${ }^{4,15}$ the loss/ leaching of Fe from the surface of HFA will definitely affect the reusability and stability of HFA and then, inevitably, it will further affect the treatment efficiency of organic wastewater.

The reusability of the HFA was evaluated under the reaction conditions of HFA $\left(20.0 \mathrm{~g} \mathrm{~L}^{-1}\right), \mathrm{H}_{2} \mathrm{O}_{2}\left(170 \mathrm{mg} \mathrm{L}^{-1}\right), p$-NP $(100 \mathrm{mg}$ $\left.\mathrm{L}^{-1}\right), \mathrm{pH} 2.0$ and a temperature of $25^{\circ} \mathrm{C}$. The catalytic behaviour of HFA was tested in 14 consecutive experimental runs. As shown in Fig. 6, we can see that the catalytic capacity of HFA in the first nine runs does not obviously decline and the removal rate of $p$-NP stays $>91 \%$. From the tenth run, the catalytic capacity starts to reduce. Thus, HFA can be considered as a stable catalyst for the first nine runs of application.

We can observe that the removal rate of $p$-NP in Fig. 6 did not decrease significantly with the leaching of $\mathrm{Fe}$ into the wastewater, which could be caused by the combined action of heterogeneous and homogeneous catalysis as discussed below.

In addition, this also indicates that heterogeneous catalysis could play a more important role than homogeneous catalysis because the leached ratio of Fe became smaller and smaller with the reuse of HFA revealing that there was less and less dissolved Fe in solution with repeated usage (Table 6).

Compared to previous studies, ${ }^{47-49}$ the modified CFA catalyst (i.e., HFA) is more stable and reusable than the catalysts in other studies, which can be reused 6 times, ${ }^{47} 3$ times $^{48}$ and 4 times. ${ }^{49}$

The slow decay of the catalytic capacity of HFA contributes to the loss of active sites displayed in the form of $\mathrm{Fe}_{2} \mathrm{O}_{3}$ on the



Fig. 6 Reusability and stability of the HFA catalyst for the degradation of $p-\mathrm{NP}\left(C_{p-\mathrm{NP}}=100 \mathrm{mg} \mathrm{L}^{-1}, \mathrm{pH}=2.0, C_{\mathrm{H}_{2} \mathrm{O}_{2}}=170 \mathrm{mg} \mathrm{L}^{-1}, T=25^{\circ} \mathrm{C}\right.$, $C_{\mathrm{HFA}}=20.0 \mathrm{~g} \mathrm{~L}^{-1}$, and time $=20 \mathrm{~min}$ ). 
Table 6 The $\mathrm{Fe}^{2+}$ concentration in the wastewater after the treatment of $p$-NP wastewater in every experimental run

\begin{tabular}{|c|c|c|c|c|c|c|c|c|c|c|c|c|c|c|}
\hline Experimental runs & 1 & 2 & 3 & 4 & 5 & 6 & 7 & 8 & 9 & 10 & 11 & 12 & 13 & 14 \\
\hline$\left[\mathrm{Fe}^{2+}\right] / \mathrm{mg} \mathrm{L}^{-1}$ & 0.41 & 0.33 & 0.28 & 0.22 & 0.20 & 0.18 & 0.15 & 0.12 & 0.09 & 0.08 & 0.08 & 0.07 & 0.06 & 0.05 \\
\hline
\end{tabular}

surface of the HFA. As for the catalytic capacity of other metal oxides, such as $\mathrm{Al}_{2} \mathrm{O}_{3}$, these still need to be further studied individually. In this test, the leaching of $\mathrm{Fe}$ (right $\mathrm{Y}$ axis in Fig. 6) from the surface of HFA to solution causes a severe loss of active sites even though the leached ratio of iron always decreases in the consecutive experimental runs (from 0.0051 to 0.0009 ).

\subsection{Catalytic mechanism of the HFA catalyzed Fenton-like process}

3.5.1 Test of the adsorption capacity of HFA. During the treatment of $p$-NP wastewater, HFA can adsorb $p$-NP onto its surface. In order to clarify the proportion of adsorbed $p$-NP in the total removed amount of $p$-NP, an investigation of the adsorption capacity of HFA was conducted. Under fixed experimental conditions (reaction temperature $=25{ }^{\circ} \mathrm{C}$, reaction time $=60 \mathrm{~min}$, which is long enough to reach the adsorption equilibrium, $\mathrm{pH}=2.0$, HFA loading $=10.0 \mathrm{~g} \mathrm{~L}^{-1}$, and $V_{p-\mathrm{NP}}=$ $100 \mathrm{~mL}$ ), the adsorption isotherm of $p$-NP (Fig. 7A) was obtained at different $p$-NP initial concentrations, namely, 1, 3, 7, 10, 15, 20, 30, 40, 50, 60, 70, 80, and $90 \mathrm{mg} \mathrm{L}^{-1}$.

The line in Fig. 7B was fitted using a Langmuir model (eqn (17)):

$$
m_{\mathrm{e}}^{-1}=\frac{1}{K \times m_{\mathrm{s}}} \times C_{\mathrm{e}}^{-1}+\frac{1}{m_{\mathrm{s}}}
$$

where $C_{\mathrm{e}}$ represents the equilibrium concentration of $p$-NP, mg $\mathrm{L}^{-1} ; m_{\mathrm{e}}$ is the equilibrium adsorption capacity, $\mathrm{mg}^{-1} ; m_{\mathrm{s}}$ is the adsorbed saturation concentration of $p$-NP on the surface of HFA, $\mathrm{mg} \mathrm{g}^{-1}$; and $K$ is the equilibrium adsorption constant, $\mathrm{L}$ $\mathrm{mg}^{-1}$.

We can calculate from Fig. 7B that $m_{\mathrm{s}}=0.296 \mathrm{mg} \mathrm{g}^{-1}$ and $K=0.1769 \mathrm{~L} \mathrm{mg}^{-1}$. Assuming $C_{p-\mathrm{NP}}=100 \mathrm{mg} \mathrm{L}^{-1}, V_{p-\mathrm{NP}}=100$ $\mathrm{mL}$ and HFA loading $=1.0 \mathrm{~g}$, under these conditions the maximum adsorption amount of $p$-NP by HFA is $0.296 \mathrm{mg}$ in theory, accounting for $2.96 \%$ of the total amount of $p$-NP in the $100 \mathrm{~mL}$ solution. Actually, with the passage of reaction time, the $p$-NP concentration decreases continuously, and so the adsorption amount of $p$-NP cannot reach a final value of $0.296 \mathrm{mg}$. This actual amount is so little compared to the amount that was removed by oxidation that the adsorption processes can be thought of as negligible.

3.5.2 Comparison of the chemical and physical features of HFA with those of CFA. A comparison of the chemical components of HFA with those of CFA is shown in Fig. 8A. The variation of the proportions of $\mathrm{CaO}$, metallic elements (especially $\mathrm{Fe}$ ) and LOI is the primary reason causing the effective catalytic capacity of HFA compared to that of CFA.

Some studies ${ }^{50-53}$ show that acidic conditions are appropriate in Fenton/Fenton-like processes; a higher $\mathrm{pH}$ could result in a remarkable reduction of the treatment efficiency of organic wastewater. Therefore, the elimination of $\mathrm{CaO}$ from CFA is necessary because the dissolution of $\mathrm{CaO}$ in water can lead to an obvious increase in the $\mathrm{pH}$ by generating $\mathrm{CaOH}$. As shown in Fig. 8A, the proportion of $\mathrm{CaO}$ reduced to $1.6 \%$ (HFA) from $10.3 \%$ (CFA), indicating that the modification of CFA removed most of the $\mathrm{CaO}$. This result is confirmed by the XRD results (Fig. 8B). We can see from Fig. 8B that all of the samples have peak 1 and peak 2 in their spectra, which are the peaks of quartz and mullite, respectively. However, the new and reused HFA lack peak 3, which represents $\mathrm{CaO}$.

Additionally, the mass fraction of $\mathrm{Fe}_{2} \mathrm{O}_{3}$ and the LOI changed as well. As shown in Fig. 8A, the $\mathrm{HNO}_{3}$ modification does not decrease the proportion of $\mathrm{Fe}_{2} \mathrm{O}_{3}$, but increases it (from $4.9 \%$ to $5.7 \%$ ), which is helpful for increasing the catalytic capacity of the HFA. The LOI is the index of organics that are not burned completely during the burning. The carbon particles included in the LOI can cover the surface of the active sites of HFA and
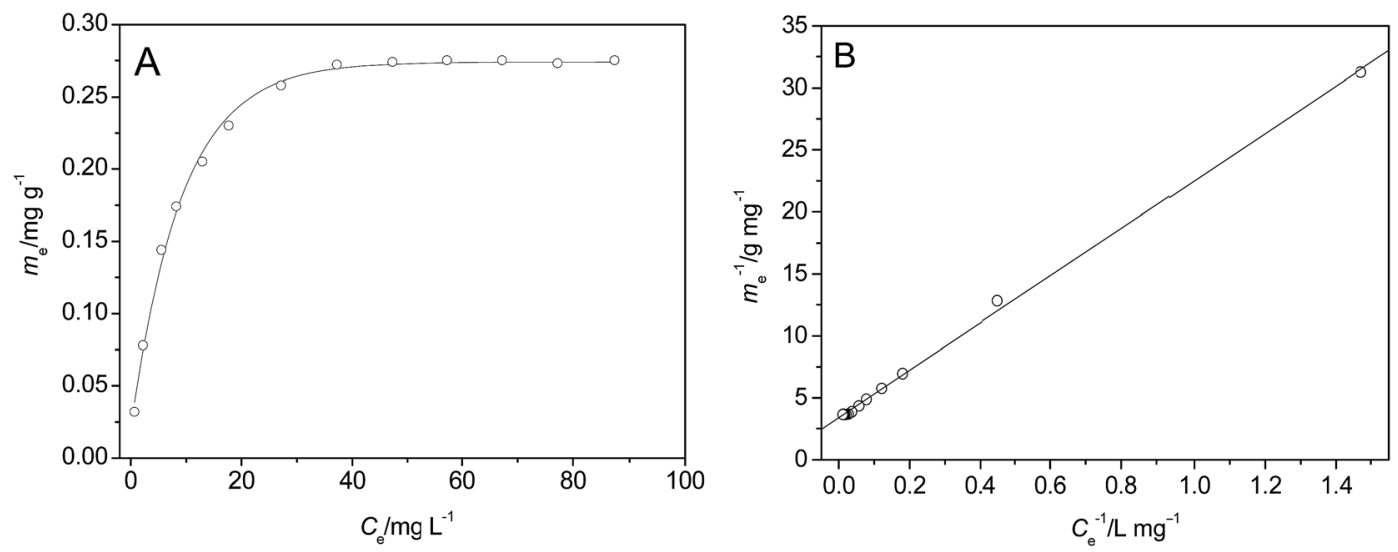

Fig. 7 Adsorption isotherms of $p$-NP on the surface of HFA (A) and the fitting of the data using Langmuir model $(\mathrm{B})\left(T=25^{\circ} \mathrm{C}, t=60 \mathrm{~min}, \mathrm{pH}=\right.$ 2.0, $C_{\mathrm{HFA}}=10.0 \mathrm{~g} \mathrm{~L}^{-1}$, and $V_{p-\mathrm{NP}}=100 \mathrm{~mL}$ ). 

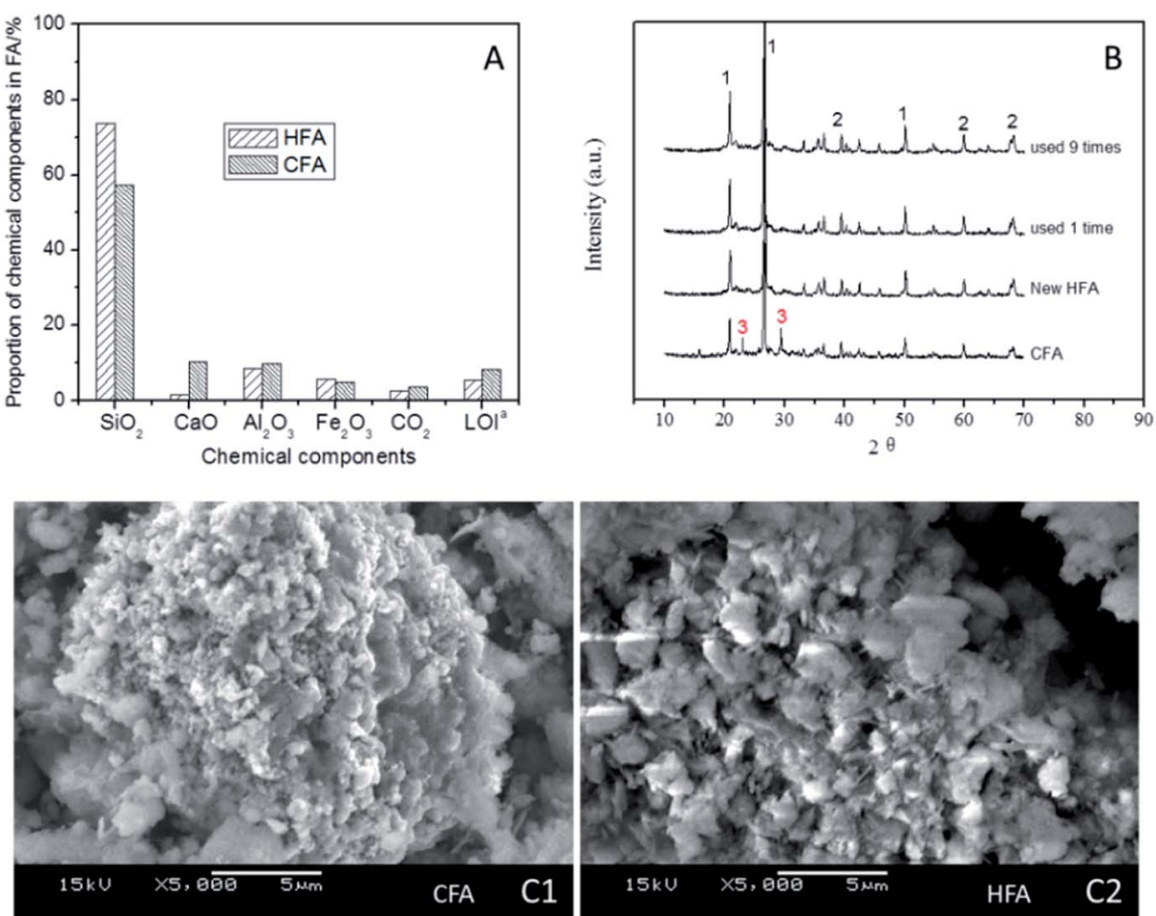

Fig. 8 Variations of physicochemical properties after CFA was modified to HFA. (A) A comparison of the chemical components of HFA and CFA ( ${ }^{a}$ : LOI means loss of ignition, it was determined after HFA and CFA were burned at $800^{\circ} \mathrm{C}$ for 24 hours); (B) a comparison of XRD data for the CFA, the new HFA, the HFA that was reused 1 time and the HFA that was reused 9 times; and (C) a comparison of SEM photographs between CFA and the new HFA.

then decrease the catalytic capacity. The $\mathrm{HNO}_{3}$ modification decreased the LOI proportion from $8.2 \%$ to $5.5 \%$, and this actually "increases" the number of active sites by reducing the cover area of the carbon particles.

Besides the comparison of the chemical components, an investigation of the physical features of HFA and CFA was conducted as well. The results show that both the specific surface area and pore volume of CFA are increased from $11.9 \mathrm{~m}^{2}$ $\mathrm{g}^{-1}$ (CFA) to $30.0 \mathrm{~m}^{2} \mathrm{~g}^{-1}$ (HFA) and from $61.7 \mu \mathrm{L} \mathrm{g}^{-1}$ (CFA) to $68.0 \mu \mathrm{L} \mathrm{g}^{-1}$ (HFA), respectively. This result is confirmed qualitatively by the SEM images (Fig. 8C). From Fig. 8C1 we can see that the morphology of CFA is presented as a bulk structure while the HFA in Fig. 8C2 shows a honeycomb structure. This reflects the increase of the specific surface area and pore volume visually.

The above changes have important implications on the increase in the adsorption capacity and the extension of the adsorption time, which is critical to the surface catalytic oxidation of organic pollutants (see Section 3.5.3).

3.5.3 Proposed reactions occurring on the surface of HFA and in the solution. Due to the existence of active sites on the surface of HFA and dissolution of Fe from the surface of HFA, the degradation of $p$-NP can occur on the surface of HFA and in the solution. The reactions that occur on the surface of HFA accord with the Haber-Weiss mechanism. ${ }^{54-56}$ The ferric ions on the surface of the HFA ( $\left.\equiv \mathrm{Fe}^{\mathrm{III}}\right)$ can be reduced to ferrous ions via reactions (18)-(20), and then ${ }^{\circ} \mathrm{OH}$ is generated subsequently on the surface of HFA through reaction (21). During the reaction, $p$-NP can be adsorbed on the surface of HFA (s-HFA) (eqn
(22)) and oxidized by ${ }^{\circ} \mathrm{OH}$ directly (eqn (23)) without needing to spread into the solution.

$$
\begin{gathered}
\equiv \mathrm{Fe}^{\mathrm{III}}+\mathrm{H}_{2} \mathrm{O}_{2} \leftrightarrow \equiv \mathrm{Fe}^{\mathrm{III}}\left(\mathrm{H}_{2} \mathrm{O}_{2}\right) \\
\equiv \mathrm{Fe}^{\mathrm{III}}\left(\mathrm{H}_{2} \mathrm{O}_{2}\right) \rightarrow \equiv \mathrm{Fe}^{\mathrm{II}} \mathrm{OOH}+\mathrm{H}^{+} \\
\equiv \mathrm{Fe}^{\mathrm{II}} \mathrm{OOH} \leftrightarrow \equiv \mathrm{Fe}^{\mathrm{II}}+\mathrm{HO}_{2} \cdot \mathrm{O}_{2} \cdot{ }^{-} \\
\equiv \mathrm{Fe}^{\mathrm{II}}+\mathrm{H}_{2} \mathrm{O}_{2} \rightarrow \equiv \mathrm{Fe}^{\mathrm{III}}+\mathrm{OH}^{-}+\cdot \mathrm{OH} \\
\mathrm{s}-\mathrm{HFA}+p-\mathrm{NP} \leftrightarrow \mathrm{s}-\mathrm{HFA}(p-\mathrm{NP})_{n} \\
\mathrm{~s}-\mathrm{HFA}(p-\mathrm{NP})_{n}+\cdot \mathrm{OH} \rightarrow \mathrm{s}-\mathrm{HFA}+\text { product }
\end{gathered}
$$

The elimination of $p$-NP in the solution is analogous to the homogeneous Fenton-like reaction. As shown in eqn (1), ${ }^{\circ} \mathrm{OH}$ can be generated by the reaction of dissolved $\mathrm{Fe}^{2+}$ with $\mathrm{H}_{2} \mathrm{O}_{2}$ and $p$-NP can be degraded (eqn (24)) by the diffused ${ }^{\circ} \mathrm{OH}$ from the surface of HFA and the generated ${ }^{\circ} \mathrm{OH}$ in the solution.

$$
p \text {-NP }+{ }^{\cdot} \mathrm{OH} \rightarrow \text { product }
$$

\section{Conclusions}

The CFA modified by nitric acid was applied as a catalyst in a Fenton-like process and its performance was studied in $p$-NP wastewater treatment. The maximum adsorption amount of 
HFA occupies $2.96 \%$ of the total amount of $p$-NP when the HFA loading is $10.0 \mathrm{mg} \mathrm{L}^{-1}$, indicating that the adsorption can be negligible in the treatment of wastewater. Under the optimum conditions (a reaction time of $60 \mathrm{~min}, C_{\mathrm{H}_{2} \mathrm{O}_{2}}$ of $170 \mathrm{mg} \mathrm{L}^{-1}, C_{\mathrm{HFA}}$ of $10.0 \mathrm{~g} \mathrm{~L}^{-1}$, pH of 2.0 , and a mixing speed of $150 \mathrm{rpm}$ ), $98 \%$ of the $p$-NP was removed at room temperature. The $\mathrm{H}_{2} \mathrm{O}_{2}$ dosage and $\mathrm{pH}$ must be controlled at appropriate values $\left(170 \mathrm{mg} \mathrm{L}^{-1}\right.$ and 2.0, respectively) for avoiding the invalid decomposition/ consumption of $\mathrm{H}_{2} \mathrm{O}_{2} /{ }^{\circ} \mathrm{OH}$ and the oxidation of ferrous ions. The catalytic capacity of HFA is sensitive to the change of treatment temperature and a higher reaction temperature is helpful for simultaneously increasing the treatment efficiency and decreasing the treatment time. HFA has favourable stability and reusability, as it can be used 9 times with a $>91 \%$ removal rate of $p$-NP. The nitric acid modification activates the CFA via increasing the $\mathrm{Fe}_{2} \mathrm{O}_{3}$ proportion, reducing the $\mathrm{CaO}$ and LOI proportion, and via increasing the specific surface area and pore volume. The degradation of $p$-NP can occur on the surface of HFA and in the solution, and the latter is similar to the homogeneous Fenton-like process.

\section{References}

1 Z. Wan and J. L. Wang, RSC Adv., 2016, 105, 103523-103531. 2 N. Flores, I. Sirés, J. A. Garrido, F. Centellas, R. M. Rodríguez, P. L. Cabot and E. Brillas, J. Hazard. Mater., 2016, 319, 3-12.

3 M. R. Carrasco-Díaz, E. Castillejos-López, A. Cerpa-Naranjo and M. L. Rojas-Cervantes, Chem. Eng. J., 2016, 304, 408-418. 4 C. Khatri and A. Rani, Fuel, 2008, 87, 2886-2892.

5 K. I. Andersson, M. Eriksson and M. Norgren, Ind. Eng. Chem. Res., 2011, 50, 7733-7739.

6 A. M. Cardoso, A. Paprocki, L. S. Ferret, C. M. N. Azevedo and M. Pires, Fuel, 2015, 139, 59-67.

7 M. Visa, L. Isac and A. Duta, Appl. Surf. Sci., 2012, 258, 63456352.

8 M. Visa, Powder Technol., 2016, 294, 338-347.

9 M. Visa and A. M. Chelaru, Appl. Surf. Sci., 2014, 303, 14-22.

10 Q. Zhou, C. J. Yan and W. J. Luo, Mater. Des., 2016, 92, 701709.

11 P. Duan, C. J. Yan, W. Zhou and D. M. Ren, Ceram. Int., 2016, 42, 13507-13518.

12 M. Visa, L. Andronic and A. Duta, J. Environ. Manage., 2015, 150, 336-343.

13 A. M. Cardoso, M. B. Hom, L. S. Ferret, C. M. N. Azevedo and M. Pires, J. Hazard. Mater., 2015, 287, 69-77.

14 G. X. Qi, X. F. Lei, L. Li, C. Yuan, Y. L. Sun, J. B. Chen, J. Chen, Y. Wang and J. M Hao, Chem. Eng. J., 2015, 279, 777-787.

15 M. Ahmaruzzaman, Prog. Energy Combust. Sci., 2010, 36, 327-363.

16 J. B. Zhang, S. P. Li, H. Q. Li and M. M. He, Fuel Process. Technol., 2016, 151, 64-71.

17 Y. Flores, R. Flores and A. A. Gallegos, J. Mol. Catal. A: Chem., 2008, 281, 184-191.

18 C. J. An, S. Q. Yang, G. H. Huang, S. Zhao, P. Zhang and Y. Yao, Fuel, 2016, 165, 264-271.

19 N. Koshy and D. N. Singh, J. Mater. Civ. Eng., 2016, 28, 04016126.
20 S. Subramanian, G. Pande, G. D. Weireld, J. M. Giraudon, J. F. Lamonier and V. S. Batra, Ind. Crops Prod., 2013, 49, 108-116.

21 M. Martin-Hernandez, J. Carrera, J. Perez and M. E. SuarezOjeda, Water Res., 2009, 43, 3871-3883.

22 K. Huang, K. Inoue, H. Harada, H. Kawakita and K. Ohto, Trans. Nonferrous Met. Soc. China, 2011, 21, 1422-1427.

23 F. Pacheco-Torgal and S. Jalali, Construct. Build. Mater., 2009, 23, 3485-3491.

24 M. I. Muñoz, A. J. Aller and D. Littlejohn, Mater. Chem. Phys., 2014, 143, 1469-1480.

25 B. A. Labaran and M. S. Vohra, Desalin. Water Treat., 2016, 57, 16034-16052.

26 N. N. Wang, T. Zheng, G. S. Zhang and P. Wang, J. Environ. Chem. Eng., 2016, 4, 762-787.

27 N. N. Wang, T. Zheng, J. P. Jiang and P. Wang, Chem. Eng. J., 2015, 260, 386-392.

28 Y. Baba, T. Yatagai, T. Harada and Y. Kawase, Chem. Eng. J., 2015, 277, 229-241.

29 S.-Q. Liu, L.-R. Feng, N. Xu, Z.-G. Chen and X.-M. Wang, Chem. Eng. J., 2012, 203, 432-439.

30 P. A. Soares, M. Batalha, S. M. A. G. U. Souza, R. A. R. Boaventura and V. J. P. Vilar, J. Environ. Manage., 2015, 152, 120-131.

31 N. Daneshvar, M. A. Behnajady and Y. Z. Asghar, J. Hazard. Mater., 2007, 139, 275-279.

32 S.-P. Sun and A. T. Lemley, J. Mol. Catal. A: Chem., 2011, 349, 71-79.

33 D. Wan, W. B. Li, G. H. Wang, L. L. Lu and X. B. Wei, Sci. Total Environ., 2017, 574, 1326-1334.

34 P. F. Collins, H. Diehl and G. F. Smith, Anal. Chem., 1959, 31, 1862-1867.

35 H. F. Zhang, X. T. Hong, S. D. Shan and X. L. Yuan, RSC Adv., 2016, 97, 95129-95136.

36 Y. H. Wang, C. J. Feng, Y. Li, J. Y. Gao and C. P. Yu, Chem. Eng. J., 2017, 307, 679-686.

37 Z. Wan and J. L. Wang, J. Hazard. Mater., 2017, 324, 653-664.

38 B. Kakavandi and A. A. Babaei, RSC Adv., 2016, 88, 8499985011.

39 S. H. Chen and D. Y. Du, J. Cent. South Univ., 2014, 21, 14481452.

40 A. L. Zhang, N. N. Wang, J. T. Zhou, P. Jiang and G. F. Liu, J. Hazard. Mater., 2012, 201-202, 68-73.

41 N. Li, P. Wang, C. Zuo, H. L. Cao and Q. S. Liu, Environ. Eng. Sci., 2010, 27, 271-280.

42 N. N. Wang, T. Zheng, J. P. Jiang, W. S. Lung, X. J. Miao and P. Wang, Chem. Eng. J., 2014, 239, 351-359.

43 B. G. Kwon, D. S. Lee, N. Kang and J. Yoon, Water Res., 1999, 33, 2110-2118.

44 X. J. Ma and H. L. Xia, J. Hazard. Mater., 2009, 162, 386-390. 45 E. Saputra, S. Muhammad, H. Q. Sun, H. M. Ang, M. O. Tade and S. B. Wang, Catal. Today, 2012, 190, 68-72.

46 M. R. Becelic-Tomin, M. B. Dalmacija, B. D. Dalmacija, L. M. Rajic and D. D. Tomasevic, Hem. Ind., 2012, 66, 485494.

47 G. Q. Gan, J. Liu, Z. X. Zhu, Z. Yang, C. L. Zhang and X. H. Hou, Chemosphere, 2017, 168, 254-263. 
48 M. R. Carrasco-Díaz, E. Castillejos-López, A. Cerpa-Naranjo and M. L. Rojas-Cervantes, Chem. Eng. J., 2016, 304, 408-418.

49 J. J. Zhang, X. H. Zhang and Y. F. Wang, RSC Adv., 2016, 16, 13168-13176.

50 M. Usman, K. Hanna and S. Haderlein, Sci. Total Environ., 2016, 569, 179-790.

51 W. Q. Pan, G. S. Zhang, T. Zheng and P. Wang, RSC Adv., 2015, 5, 27043-27051.

52 M. Hartmann, S. Kullmann and H. Keller, J. Mater. Chem., 2010, 20, 9002-9017.
53 M. Moussavi and S. Matavos-Aramyan, Korean J. Chem. Eng., 2016, 33, 2384-2391.

54 L. Gu, N. W. Zhu and P. Zhou, Bioresour. Technol., 2012, 118, 638-642.

55 I. S. X. Pinto, P. H. V. V. Pacheco, J. V. Coelho, E. Lorenc, J. D. Ardisson, J. D. Fabris, P. P. de Souza, K. W. H. Krambrock, L. C. A. Oliveira and M. C. Pereira, Appl. Catal., B, 2012, 119-120, 175-182.

56 R. C. C. Costa, F. C. C. Moura, J. D. Ardisson, J. D. Fabris and R. M. Lago, Appl. Catal., B, 2008, 83, 131-139. 